\title{
EFFECT OF HOSPITAL ACCREDITATION ON PATIENT SAFETY CULTURE AND SATISFACTION: A SYSTEMATIC REVIEW
}

\author{
Yunita Hapsari, Amal Chalik Sjaaf
}

Faculty of Public Health, Universitas Indonesia

\begin{abstract}
Background: Hospital accreditation is carried out to improve the quality of hospital services and patient safety. This study aimed to statistically review the effect of hospital accreditation on patient safety culture and satisfaction.

Subjects and Methods: A systematic review was conducted through articles searching. Four electronic databases namely PubMed, ProQuest, Scopus, and EBSCO were used in this study. The keywords were "hospital accreditation", "patient safety culture", "patient satisfaction", "improving", and "impact". The inclusion criteria in this study were articles in the span of ten years of publication, and using English. The articles were selected by PRISMA flow diagram.

Results: Ten journal reported that accreditation had a significant influence on patient safety culture. There was difference in patient satisfaction among accredited and non-accredited hospitals, but it was not statistically significant. Two articles mentioned that patient satisfaction was driven by hospital physical facilities. Patient safety culture after hospital accreditation was associated with commitment and support from all hospital staff and leadership. Service quality and patient satisfaction were associated with ongoing evaluation of the accreditation implementation.

Conclusion: Hospital accreditation has an effect on patient safety culture and satisfaction. Improving patient safety culture after hospital accreditation requires commitment and support from al hospital staff and leadership. Ongoing evaluation of the accreditation implementation needs to be carried out to improve service quality and patient satisfaction.
\end{abstract}

Keywords: accreditation, patient safety, culture, patient satisfaction, hospital

\section{Correspondence:}

Yunita Hapsari. Faculty of Public Health, Universitas Indonesia, Depok, West Java. Email: yunitahaphap@gmail.com. Mobile: 081808101539.

\begin{abstract}
BACKGROUND
Accreditation is a learning process and continuous quality improvement in maintaining the quality of services of patient health with a predetermined standard (Al-Awa et al., 2012). One of the efforts carried out by countries around the world in improving performance are through accreditation, because it is an influential mechanism for assessing the performance of health care organizations (Pomey et al., 2010, Jaafaripooyan et al., 2011).
\end{abstract}

Accreditation is considered a key component and prioritizes patient safety and quality of service. In addition, accreditation is useful for improving risk management, providing patient safety culture in hospitals, controlling costs, making management effecttive, and building initiative in term of patient safety from organizations that participate in accreditation. Achieving accreditation is a strong statement to show the public about the organization's efforts to provide the highest quality service. (Marzban et al., 2017; Sack et al., 2011).

Nowadays, international accreditation organizations require assessing patient safety culture to identify strengths and weaknesses of patient safety culture, evaluating employees in teamwork, management and leadership that support patient safety, frequency of incident reporting, and identifying existing 
patient safety culture problems (Deilkås and Hofoss, 2008; El-Jardali et al., 2011).

The truth of the statement of "hospital accreditation will ensure good quality health service" is doubtful. It shows the need to provide evidence that accreditation procedures can surely improve health services, thus increasing patient satisfaction (Sack et al., 2010; Pomey et al., 2010).

However, the impact of accreditation on quality of services and patient safety is little known (Al-Awa et al., 2012). A previous study on the impact of hospital accreditation status on patient satisfaction showed that there was non-significant impact of hospital accreditation on patient satisfaction (Hayati, et al., 2010; C. Sack et al., 2011).

Another study showed that there were differences and there was no correlation between quality of services and the accreditation program based on the patient perspective (Aboshaiqah et al., 2016). According to Devkaran and O'Farrell (2015), accreditation standards might not be sensitive enough to evaluate the actual improvement. Therefore, the evaluation can be seen on the spot only during the accreditation survey. In addition, the impact is over after the survey is completed.

\begin{tabular}{l}
\hline \multicolumn{2}{c}{ SUBJECTS AND METHOD } \\
\hline 1. Study Design \\
This was systematic review study using PRIS- \\
MA-P (Preferred Reposting Items for \\
Systematic Review and Meta-Analysis Pro- \\
tocol). The researchers searched for articles \\
from 4 databases namely PubMed, ProQuest, \\
Scopus, and EBSCO. The keywords were \\
"hospital accreditation", "patient safety \\
culture", "patient satisfaction", "improveing", \\
and "impact".
\end{tabular}

\section{Inclusion and Exclusion Criteria}

The inclusion criteria were journal articles in the span of ten years of publication and using English. Based on the investigation, there were 10 relevant articles to be reviewed. 


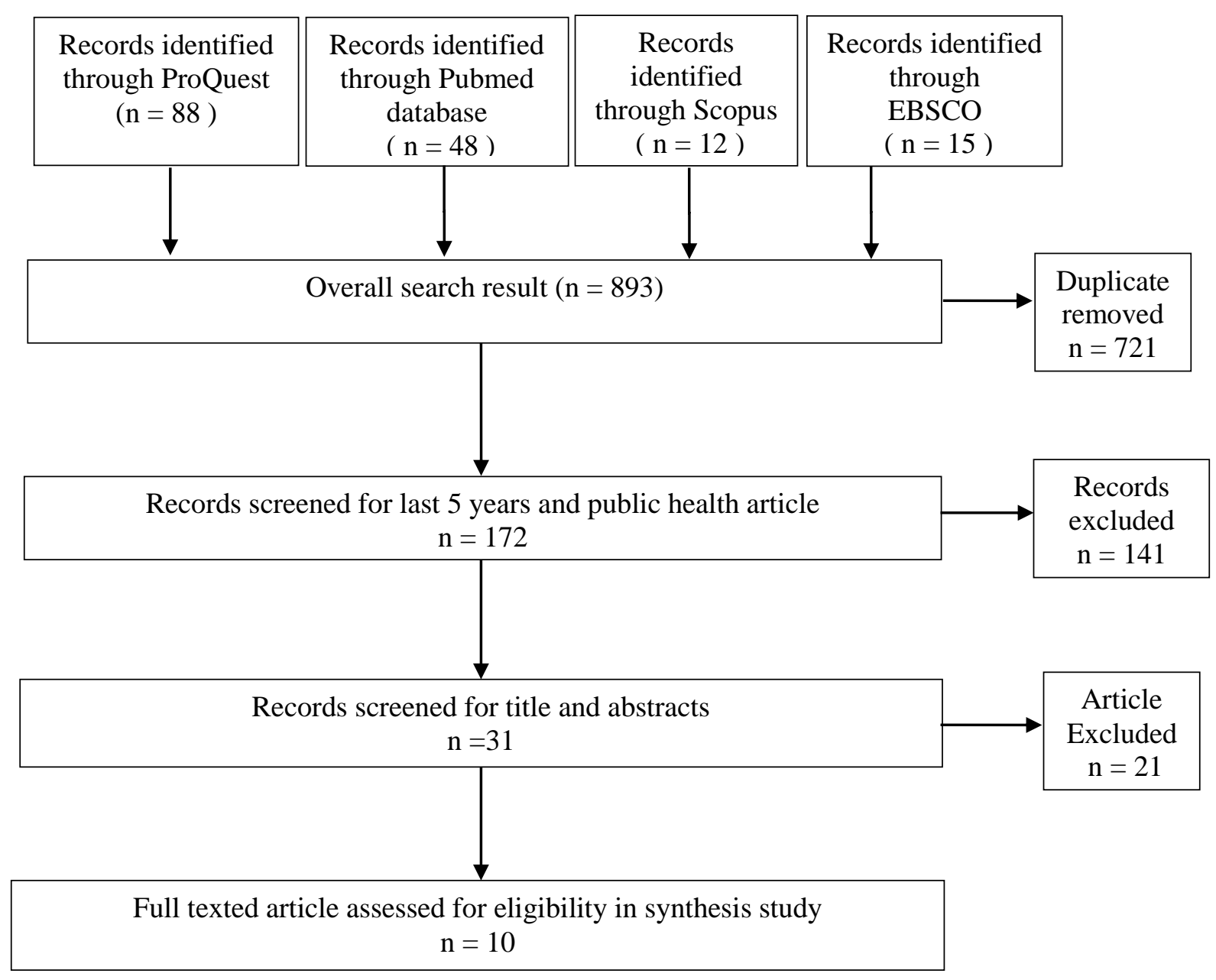

Figure 1. PRISMA Flow Diagram

\section{RESULTS}

Based on 10 articles reviewed, 3 articles mentioned that the implementation of patient safety culture significantly increased after accreditation. Accredited hospital had a better overall perceived safety, including the frequency of reporting incidents/safety incidents compared to hospitals that had not been accredited yet. Four other articles stated that there was no significant difference between accredited and non-accredited hospitals and patient satisfaction. This means that there is no correlation between hospital accreditation and patient satisfaction. However, 2 other articles mentioned that patient satisfaction increased after accredittation. 
Table 1. Article of systematic review

\begin{tabular}{|c|c|c|c|c|c|c|}
\hline No & $\begin{array}{l}\text { Author } \\
\text { (year) }\end{array}$ & Tittle & Place & Study Design & Results & Conclusion \\
\hline 1 & $\begin{array}{l}\text { Mohebbifar et } \\
\text { al. (2017) }\end{array}$ & $\begin{array}{l}\text { Association between } \\
\text { Hospital Accreditation and } \\
\text { Patient Satisfaction: A } \\
\text { Survey in the Western } \\
\text { Province of Iran }\end{array}$ & Iran & cross-sectional & $\begin{array}{l}\text { There was a correlation between patient } \\
\text { satisfaction scores and length of stay, } \\
\text { type of hospital, human resources, } \\
\text { physical structure and medical devices, } \\
\text { information and education, access to } \\
\text { services, management and service } \\
\text { coordination. There was non-significant } \\
\text { correlation between hospital } \\
\text { accreditation and patient satisfaction. }\end{array}$ & $\begin{array}{l}\text { The study states the } \\
\text { importance of developing } \\
\text { an accreditation system } \\
\text { based on outcome } \\
\text { parameters and providing } \\
\text { responsive services to } \\
\text { patients that can have a } \\
\text { positive impact on their } \\
\text { satisfaction. }\end{array}$ \\
\hline 2 & $\begin{array}{l}\text { Al-Awa et al. } \\
(2012)\end{array}$ & $\begin{array}{l}\text { Benchmarking the post- } \\
\text { accreditation patient } \\
\text { safety culture at King } \\
\text { Abdulaziz University } \\
\text { Hospital }\end{array}$ & $\begin{array}{l}\text { Jeddah, } \\
\text { Saudi } \\
\text { Arabia. }\end{array}$ & $\begin{array}{l}\text { Cross-sectional } \\
\text { retrospective } \\
\text { and } \\
\text { prospective } \\
\text { study post- } \\
\text { accreditation }\end{array}$ & $\begin{array}{l}605 \text { nurses who answered the } \\
\text { questionnaires strongly agreed that } \\
\text { accreditation increased the perception of } \\
\text { patient safety culture }\end{array}$ & $\begin{array}{l}\text { Accreditation is } \\
\text { significantly related to } \\
\text { patient safety culture }\end{array}$ \\
\hline 3 & $\begin{array}{l}\text { Sack et al. } \\
\text { (2010) }\end{array}$ & $\begin{array}{l}\text { Challenging the holy grail } \\
\text { of hospital accreditation: } \\
\text { A cross sectional study of } \\
\text { inpatient satisfaction in } \\
\text { the field of cardiology }\end{array}$ & German & Cross-sectional & $\begin{array}{l}\text { "Recommendation rate } \\
\text { of a given hospital" for accredited } \\
\text { hospitals (65.6\%, 95\% Confidence } \\
\text { Interval (CI) } 63.4-67.8 \% \text { ) and non- } \\
\text { accredited hospitals (65.8\%, } 95 \% \text { CI } 63.1 \\
\text { - } 68.5 \% \text { ) showed non-significant } \\
\text { differences }\end{array}$ & $\begin{array}{l}\text { Hospital accreditation can } \\
\text { increase quality of service, } \\
\text { but it does not increase } \\
\text { patient satisfaction. }\end{array}$ \\
\hline 4 & $\begin{array}{l}\text { Hajali et al. } \\
\text { (2014) }\end{array}$ & $\begin{array}{l}\text { Exploring the Relationship } \\
\text { between Accreditation and } \\
\text { Patient Satisfaction - The } \\
\text { Case of Selected Lebanese } \\
\text { Hospitals }\end{array}$ & Lebanon & Cross sectional & $\begin{array}{l}\text { Most of the patients ( } 76.34 \%) \text { were not } \\
\text { satisfied with the quality of service. There } \\
\text { was statistically non-significant } \\
\text { correlation between the classification of } \\
\text { accreditation and patient satisfaction. } \\
\text { However, tangibility dimensions that } \\
\text { reflect structural aspects of the hospital } \\
\text { such as physical facilities and equipment } \\
\text { were related to patient satisfaction. }\end{array}$ & $\begin{array}{l}\text { This study confirms the } \\
\text { importance of considering } \\
\text { patient perspectives in the } \\
\text { development and } \\
\text { implementation of } \\
\text { accreditation systems. } \\
\text { Accreditation is not the } \\
\text { only cause of patient } \\
\text { satisfaction. However, } \\
\text { hospitals are asked to }\end{array}$ \\
\hline
\end{tabular}

The $6^{\text {th }}$ International Conference on Public Health Best Western Premier Hotel, Solo, Indonesia, October 23-24, $2019 \mid 550$ 
Investigation of the

conditions affecting the

joining of Hungarian

$5 \quad$ al. (2018)

hospitals to an

accreditation program:

a cross-sectional study

$6 \begin{aligned} & \text { Algahtani et } \\ & \text { al. (2017) }\end{aligned}$

Perception of hospital accreditation among

health professionals in Saudi Arabia

Perceptions of nurses on the impact of accreditation on quality of care: A survey in a hospital in Turkey
Jeddah,

Saudi

Arabia.

\section{Cross-}

sectional

Hospitals with project preparation for four of the six activities investigated. The

head of quality management had a better opinion about the benefit of quality management, surgical safety, and clinical audit.

Hospital accreditation received good responses from 901 health professions. The mean (standard deviation) score on the 5-point Likert scale was 3.79 (o.68)

for participation in accreditation, 3.85 (0.84) for benefits, and 3.54 (1.01) for the quality of results.

There was a statistically significant positive correlation between the dependent variable (quality outcome) and the independent variables (the benefits of accreditation and employee

Hacettepe

Adult

Hospital,

Cross sectional

Turkey showed R2 = 0.46 and how far the independent variables explained the accreditation programs were better in

adopt complementary ways to increase patient satisfaction.

If accredited hospitals in the future are better than other hospitals, the increase can only be contributed to accreditation.

Accreditation has a positive impact on the implementation and change processes in hospitals, thus improving patient care services and other health services.

Hospital accreditation has a positive impact on quality outcomes, especially on the quality of care provided to patients dependent variable was $46.1 \%$, which was and patient satisfaction. a high level. Patient satisfaction scores increased after accreditation. 


\section{El-Jardali et Predictors and outcomes of patient safety culture}

al. (2011) in hospitals

Status of accessible quality indices in the hospitals of

Marzban et al. Shahid Beheshti

(2017)

University of Medical

Sciences according to accreditation in 2015

The Effect of Accreditation on Patient Satisfaction in Public Healthcare

10 Joseph (2018) Delivery: A Comparative Study of Accredited and Non-accredited Hospitals in Kerala
Accredited hospitals had much higher

Lebanon

Cross-sectiona

perception of patient safety and

frequency of incident reporting than nonaccredited hospitals.

The most preferred patient satisfaction index was emergency and inpatient

Beheshti

University

of Medical

Cross-sectional

Sciences

Tehran,

Iran

Kerala, India patient satisfaction in the excellent first degree hospitals was lower than first degree hospitals

There was non-significant impact

Cross-sectional
Incidence reporting communication,

leadership and

management of patient

safety, staff, and

accreditation are

identified as key

predictors of patient

safety culture. Further

study is needed to

understand the

correlation between

patient safety culture and

clinical outcomes.

There is non-significant difference between the index of hospital care processes and various levels of accreditation.

Making accreditation a

useful instrument requires indicators to assess quality based on patien outcomes periodically. 


\section{DISCUSSION}

In the accreditation process, an organization will commit to improve quality in the implementation of patient safety. It is evidenced by the increased teamwork in the unit and the significant improvement in the implementation of a patient safety culture after accreditation (Al-Awa et al., 2012).

Accredited hospitals had a much higher perception of patient safety and frequency of incident reporting than non-accredited hospitals (El-Jardali et al., 2011). It is in line with a previous study conducted by ElJardali (2010) that respondents who worked in an accredited hospital were more likely to report incidents, have an increase in patient safety perceptions, and feel the quality of service increased with accreditation. The improvement in the implementation of patient safety culture could be caused by training and learning about patient safety during the accreditation process and hospital staff for example nurses feel the positive benefits of accreditation and carry out tasks by implementing standards (Wanderlei and Montagna, 2018; Yildiz and Kaya, 2014).

However, there was non-significant correlation between accreditation and patient satisfaction. This is in line with a previous study (Hayati et al., 2010; Sack et al., 2011) that there was non-significant differrence between accredited and non-accredited hospitals and patient satisfaction. Patients gave different rank satisfaction with the services they receive, it caused by the type of service received, their expectations about service, perceptions and experience of the service (Hayati et al., 2010).

Patient satisfaction in accredited hospitals was not in quality of services, but in the tangibility dimension, namely the structural aspects of the hospital such as physical facilities and equipment (Haj-ali et al., 2014; Mohebbifar et al., 2017; Yildiz and Kaya, 2014). It is challenging because the accredita- tion is considered to only ensure the hospital has fulfilled the predefined standards but does not see in terms of quality of care or clinical results (Devkaran and O'Farrell, 2015). However hospital staff felt accredittation had a positive impact on the process and implementation changes in the hospital (Algahtani et al., 2017; Yildiz and Kaya, 2014)

Improving patient safety culture after hospital accreditation requires commitment and support from all staff at the hospital, especially from hospital leaders. Accreditation should not only be a standard reference in the hospital change process but also think about how the process improves the quality of care to obtain positive clinical outcomes as well. Ongoing evaluation of the implementation of accreditation needs to be carried out in order to improve quality of services and patient satisfaction.

\section{REFERENCES}

Aboshaiqah AE, Alonazi WB, Patalagsa JG (2016). Patients' assessment of quality of care in public tertiary hospitals with and without accreditation: comparative cross-sectional study. Journal of Advanced Nursing, 72(11): 2750-2761. https://doi.org/10.1111/jan.13025

Al-Awa B, Al Mazrooa A, Rayes O, El Hati T, Devreux I, Al-Noury K, El-Deek B. S. (2012). Benchmarking the post-accreditation patient safety culture at King Abdulaziz University Hospital. Annals of Saudi Medicine, 32(2): 143-150. https://doi.org/10.5144/0256-4947.2012.143 Algahtani H, Aldarmahi A, Manlangit J, Shirah B. (2017). Perception of hospital accreditation among health professionals in Saudi Arabia. Annals of Saudi Medicine, 37(4): 326-332. https://doi.org/10.5144/0256-4947.2017.326

Braithwaite J, Greenfield D, Westbrook J, Pawsey M, Westbrook M, Gibberd R, Lancaster J. (2010). Health service accreditation as a predictor of clinical 
and organisational performance: a blinded, random, stratified study. 14-21. https://doi.org/10.1136/qshc.2009.033928

Deilkås ET, Hofoss D (2008). Psychometric properties of the Norwegian version of the Safety Attitudes Questionnaire (SAQ), Generic version (Short Form 2006). BMC Health Services Research, 8: 1-10. https://doi.org/10.1186/1472-6963-8191

Devkaran S, O'Farrell P N. (2015). The impact of hospital accreditation on quality measures: An interrupted time series analysis Quality, performance, safety and outcomes. BMC Health Services Research, 15(1). https://doi.org/10.1186/s12913-015-0784-5

Dombrádi V, Margitai B, Dózsa C, BárdosCsenteri O K, Sándor J, Gáll T, Godény S. (2018). Investigation of the conditions affecting the joining of Hungarian hospitals to an accreditation programme: A crosssectional study. BMJ Open, 8(2), 12-15. https://doi.org/10.1136/bmjopen-2017-019232

El-Jardali F, Dimassi H, Jamal D, Jaafar M, Hemadeh N. (2011). Predictors and outcomes of patient safety culture in hospitals. BMC Health Services Research, 11(1): 45. https://doi.org/10.1186/1472-6963-11-45

Haj-ali W, Karroum L B, Natafgi N, Kassak K. (2014). Original Article Exploring the relationship between accreditation and patient satisfaction - the case of selected Lebanese hospitals. 3(6): 341-346. https://doi.org/10.15171/ijhpm.2014.116 Hayati I N, Azimatun N A, Rozita H, Ezat W A S, Rizal A M (2010). In-patients' satisfaction in the medical and surgical wards - a comparison between accredited and non accreditated hospital in the state of Selangor. Malaysian Journal of Community Health, 16(1), 60-68.
Jaafaripooyan E, Agrizzi D, Akbari-Haghighi F. (2011). Healthcare accreditation systems: Further perspectives on performance measures. International Journal for Quality in Health Care, 23(6): 645656. https://doi.org/10.1093/intqhc/mzro63

Joseph S. (2018). The Effect of Accreditation on Patient Satisfaction in Public Healthcare Delivery : A Comparative Study of Accredited and Non-accredited Hospitals in Kerala. 10(2): 123-137.

Marzban S, Ramezankhani A, Rad M R, Daneshkohan A, Najafi A. (2017). Status of accessible quality indices in the hospitals of Shahid Beheshti University of Medical Sciences according to accreditation in 2015. https://doi.org/10.4103/ATMPH.ATMPH

Pomey M, Lemieux-charles L, Champagne F, Angus D, Shabah A. (2010). Does accreditation stimulate change? A study of the impact of the accreditation process on Canadian healthcare organizations.

Sack C, Scherag A, Lütkes P, Günther W, Jöckel K. H, Holtmann G. (2011). Is there an association between hospital accreditation and patient satisfaction with hospital care? A survey of 37000 patients treated by 73 hospitals. International Journal for Quality in Health Care, 23(3): 278-283. https://doi.org/10.1093/intqhc/mzro11

Sack C, Lütkes P, Günther W, Erbel R, Jöckel K H, Holtmann G J. (2010). Challenging the holy grail of hospital accreditation: A cross sectional study of inpatient satisfaction in the field of cardiology. BMC Health Services Research, 10. https://doi.org/10.1186/1472-6963-10-120

The Joint Commission. (2015). Benefits of Joint Commission Accreditation. Benefits of Joint Commission Accreditation. Wanderlei PN, Montagna E. (2018). Formulation, implementation and evaluation 
of a distance course for accreditation in patient safety. Einstein (Sao Paulo, Brazil), 16(2): eGS4316. https://doi.org/10.1590/S1679-45082018GS4316

Yildiz A, Kaya S. (2014). Perceptions of nurs- es on the impact of accreditation on quality of care: A survey in a hospital in Turkey. Clinical Governance, 19(2): 6982. https://doi.org/10.1108/CGIJ-072013-0021 